\title{
Laparoscopic gynecological surgery in COVID-19 pandemic
}

\author{
Kallol Kumar Roy, MD, DNB, Rakhi Rai, MIGS, MS, Rinchen Zangmo, MD, DNB, Archana Kumari, MD, \\ Nilofar Noor, MD, Deepali Garg, MD
}

Department of Obstetrics and Gynaecology, All India Institute of Medical Sciences, New Delhi, India

The major concern that has confronted surgeons during the COVID-19 pandemic is the risk of infection during surgery. So far, no studies have found SARS-CoV-2 in surgical smoke, and if it was found, whether it was infectious or not is unknown. To date, no evidence shows that respiratory viruses can be transmitted through a surgical plume or an aerosolized gas. There are various advantages of laparoscopy over laparotomy that must be kept in mind in the COVID-19 era, such as early recovery and shorter hospital stay, which can greatly help to conserve valuable hospital resources, and reduced risk of spillage of blood and body fluids, which can help to reduce transmission risk; most importantly, the distance between surgeons and between surgeons and patient is greater. Certain precautionary measures can be taken to reduce SARS-CoV-2 transmission during laparoscopy. Whenever possible, it should be the surgical option of choice.

Keywords: Laparoscopy; COVID-19; SARS CoV-2; Smoke evacuation; Pneumoperitoneum

\section{Introduction}

The COVID-19 pandemic has become a global health problem, putting a strain on the health infrastructure by diverting resources to tackle this infection. It spreads through the respiratory tract via droplets [1]. Transmission by the abdominal route is not clear [2,3]. All bodily fluids and tissues should be considered as potential sources of the virus [4].

\section{Impact of COVID-19}

European Society of Gynaecological Endoscopy (ESGE), Society of American Gastrointestinal and Endoscopic Surgeons (SAGES), Royal College of Obstetricians \& Gynaecologists (RCOG), American Association of Gynecologic Laparoscopists (AAGL) stated that elective surgeries for benign diseases should be delayed with a shift of focus to emergency surgeries, thus allowing utilization of key resources in required areas, and that wherever possible, alternative medical management should be attempted [5]. Currently, surgical management should be performed only when the condition is life threatening, such as malignancies that are likely to progress and emergencies with acute symptoms requiring urgent care $[6,7]$. Laparoscopy is the best approach for certain emergency procedures, such as ruptured ectopic pregnancy and ovarian torsion [8]. However, some apprehensions do wade through the minds of surgeons worldwide about the possible risk of SARS-CoV-2 transmission through the creation of a pneumoperitoneum during laparoscopy.

Received: 2020.10.21. Revised: 2020.12.14. Accepted: 2021.1.11. Corresponding author: Rakhi Rai, MIGS, MS

Department of Obstetrics and Gynecology, All India Institute of Medical Sciences, Sri Aurobindo Marg, Ansari Nagar, New Delhi 110029, India

Email: drrakhi81@yahoo.co.in

https://orcid.org/0000-0002-8208-4126

Articles published in Obstet Gynecol Sci are open-access, distributed under the terms of the Creative Commons Attribution Non-Commercial License (http://creativecommons. org/licenses/by-nc/3.0/) which permits unrestricted non-commercial use, distribution, and reproduction in any medium, provided the original work is properly cited.

Copyright $\odot 2021$ Korean Society of Obstetrics and Gynecology 


\section{Obstetrics \& Gynecology Science}

Kallol Kumar Roy, et al. Laparoscopy in COVID-19

\section{Why has the concern about the infection been raised among surgeons during laparoscopic surgery?}

Various theories have been proposed in this regard. It has been observed that SARS-CoV-2 is found in the stools of infected patients, which raised the alarm for possible viral transmission through the abdomen $[9,10]$. Another proposed theory suggests that the pneumoperitoneum leads to the creation of a stagnant heated volume of gas in the peritoneal cavity, which can lead to concentrated aerosolization of viral particles. Hence, the sudden release of this pneumoperitoneum can promote viral transmission [1]. DNA of various viruses such as human immunodeficiency virus have been found in the surgical plume produced by electrosurgery, but the risk of viral transmission has not been proven $[11,12]$. The laparoscopic approach is in fact usually preferred over laparotomy to reduce the risk of exposing surgeons to bloodborne viruses. Even earlier pandemics of influenza virus or other coronaviruses have not shown any transmission risk through a surgical plume or pneumoperitoneum [13]. To date, no evidence shows that respiratory viruses can be transmitted through a surgical plume or an aerosolized gas [8].

\section{Advantages of laparoscopy over laparotomy}

Laparoscopy is advantageous over laparotomy due to earlier recovery and shorter hospital stay, less risk of spillage of blood and body fluids, limited exposure to surgical smoke due to the closed space of the pneumoperitoneum, reduced risk of transmission of virus particles, and greater distance between surgeons and between surgeons and patient. Hence, the blanket approach of laparotomy for all cases during the COVID-19 pandemic is not appropriate. The RCOG and British Society for Gynaecological Endoscopy (BSGE) stated that laparoscopy should be preferred over laparotomy when appropriate $[6,7]$.

Laparoscopy is an aerosol-generating procedure and is usually performed under general anesthesia. Although the risk of exposure is not proven, precautions need to be undertaken to minimize the possible risk of transmission. There is a fair risk of aerosolization during intubation and extubation
[8]. Aerosol formation also occurs during the release of $\mathrm{CO}_{2}$ during port entry and removal, instrument exchange, specimen retrieval, and pneumoperitoneum deflation. Certain precautionary measures suggested by various societies (AAGL, ESGE, BSGE, and RCOG) and laparoscopic experts, which can be used to reduce the SARS-CoV-2 transmission rate during laparoscopy, are summarized below [5-8,14-21].

\section{General recommendations}

- Postpone all non-urgent physical visits by the patients.

- Teleconsultation should be conducted wherever possible.

\section{Preoperative}

- Defer non-urgent surgeries.

- Screen patients for COVID-19 by questionnaire; if feasible according to the local protocol, virology screening should be performed preoperatively for every patient.

- In cases where urgent surgery is required and COVID-19 testing is not possible, the patient should be suspected as having COVID-19.

- If COVID-19 is suspected or confirmed on testing, surgery should be postponed if possible until complete recovery occurs. If surgery cannot be postponed, full personnel protective equipment (PPE) (impervious gown, N95 mask, eye protection, protective head gear, gloves, and shoe cover) must be used by operating room (OR) personnel.

- Informed consent regarding possible exposure to COVID-19 and the subsequent consequences should be obtained from the patient.

\section{Intraoperative}

- Separate ORs for COVID-19 patients with appropriate donning and doffing areas must be established.

- Minimize the number of personnel in the ORs.

- Limit the movement of staff in and out of the ORs.

- Laparoscopy should be performed by an experienced surgeon, and surgical training should be avoided to minimize the time of surgery.

- Disinfect trolleys with 1\% hypochlorite solution.

- Create a negative pressure environment in the ORs to reduce the transmission risk. Start air conditioners after the induction of anesthesia and temporarily stop them for approximately 20 minutes before extubation of the patient.

- Contaminated air flow should be limited by closing all OR 


\section{Obstetrics \& Gynecology Science}

Vol. 64, No. 3, 2021

doors. There should be a single exit and entry through a scrub room.

- Anesthesia monitors should be covered with plastic sheets.

- Use rapid sequence induction and intubation to avoid mechanical ventilation, thereby decreasing aerosolization of the virus from the airways.

- Use a heat and moisture exchanger filter (HMEF) between the facemask and breathing circuit as it can remove 99.9\% of $\geq 0.3 \mu \mathrm{m}$ airborne particles.

- Disinfect anesthesia machines after each use.

- The surgical team should enter the OR at least 15 minutes after the induction of anesthesia.

- Minimize the degree of the Trendelenburg position.

- Intraabdominal $\mathrm{CO}_{2}$ pressure should be kept low. Reduction in lung volume, raised airway pressure, enhanced $\mathrm{CO}_{2}$ retention, and reduced lung compliance occur secondary to the pneumoperitoneum, increasing the perioperative risk of COVID-19.

- Port incision size should be just adequate to reduce port site leakage.

- Minimize the use of energy devices in low-power settings. Monopolar diathermy pencils with attached smoke evacuators should be used if available.

- Avoid prolonged activation of energy sources to reduce the production of a surgical plume.

- Designated members of the operating team should evacuate smoke and fumes.

- A closed smoke evacuation and filtration system using an ultralow particulate air filter that can filter 0.1-micron diameter particles should be used for controlled-release filtration of surgical plumes. The suction evacuation device should be within $2 \mathrm{~cm}$ of the source of the plume as for every $1 \mathrm{~cm}$ from the source, there is a $50 \%$ loss of capture.

- Do not open ports without attaching a $\mathrm{CO}_{2}$ filter. Suck smoke using a suction device.

- Avoid frequent exchange of instruments.

- The sudden release of the pneumoperitoneum should be avoided, especially at the time of tissue extraction at the end of surgery. The abdominal cavity should be desufflated through a filtration system or tubing attached to a suction device.

- Suck the entire pneumoperitoneum before making an ancillary incision and at the end of surgery before remov- ing the trocars.

- Avoid extracorporeal knots (port needs to be opened).

- Gasless laparoscopy can be considered.

- Avoid blood/body fluid spillage at the time of tissue extraction.

- Accessory ports should be removed slowly and over a blunt probe, which is removed subsequently to decrease the risk of hernia as removal cannot be performed under vision to avoid inadvertent gas leakage. The primary port should be removed under vision after the abdomen is completely deflated.

- Use of surgical drains should be kept to a minimum.

- Suture closure devices that allow gas leakage should be avoided.

- Ports $>5 \mathrm{~mm}$ in size should be closed with a J needle device and not with an EndoClose device, which may enhance the risk of gas leakage from the abdomen.

- Fascia should be closed after desufflation.

- Path of the patient from and to the OR should be defined.

\section{Postoperative}

- COVID-19-positive patients must be shifted by a designated team wearing PPE to a designated COVID-19 ward or an Intensive Care Unit.

- Specimens should be properly labeled as COVID-19-positive specimens and transported in a proper container to reduce the transmission risk.

- Surgeons should change scrubs and take a shower.

- At least a 1-hour gap should be maintained between 2 consecutive cases.

Gupta et al. [22] used a simple, convenient approach for aerosol diffusion during laparoscopy. They used an extra gas tubing, as was used for creating the pneumoperitoneum, which was attached to another port and then attached to a central suction device for the evacuation of surgical smoke. They used this method for 23 cases with satisfactory results and no increases in operating time or surgical difficulty. Dash and Chawla [23] reported their experience of 14 cases of gynae-laparoscopy surgery, including salpingectomy for ectopic pregnancy, total laparoscopic hysterectomy, radical hysterectomy, cystectomy, cervical cerclage, and myomectomy, and found it to be a safe alternative to laparotomy. US joint professional society statement and European joint society 


\section{Obstetrics \& Gynecology Science}

Kallol Kumar Roy, et al. Laparoscopy in COVID-19

statement endorsed laparoscopy as a safe surgical approach. Regardless of the theoretical risk of SARS-CoV transmission, transmission is reduced with laparoscopy if all the due precautions are taken.

In our settings, preoperative COVID-19 testing was performed for all patients. As testing of all patients is not realistic at all times, we are taking all the above precautions in the OR to protect the health care givers against SARS-CoV-2 infection.

\section{Conclusion}

While there is not enough evidence to prove the transmission of SARS-CoV through a surgical plume and pneumoperitoneum, adequate precautions must be taken to reduce the theoretical risk at all levels, making the environment safe for health care professionals. Whenever found appropriate, laparoscopy should be the surgical choice during the pandemic.

\section{Conflict of interest}

There is no potential conflict of interest relevant to this article.

\section{Ethical approval}

This study does not require approval of the Institutional Review Board because no patient data is contained in this article.

\section{Patient consent}

Written informed consent from patients is not required as this study does not involve human participants.

\section{Funding information}

None.

\section{References}

1. Vigneswaran $Y$, Prachand VN, Posner MC, Matthews JB, Hussain M. What is the appropriate use of laparoscopy over open procedures in the current COVID-19 climate? J Gastrointest Surg 2020;24:1686-91.

2. Coccolini F, Tartaglia D, Puglisi A, Giordano C. SARSCoV-2 is present in peritoneal fluid in COVID-19 patients. Ann Surg 2020;272:e240-2.

3. Ngaserin SH, Koh FH, Ong BC, Chew MH. COVID-19 not detected in peritoneal fluid: a case of laparoscopic appendicectomy for acute appendicitis in a COVID-19-infected patient. Langenbecks Arch Surg 2020;405:353-5.

4. Angioni S. Laparoscopy in the coronavirus disease 2019 (COVID-19) era. Gynecol Surg 2020;17:3.

5. European Society for Gynaecological Endoscopy (2020). ESGE recommendations on gynaecological endoscopic surgery during Covid-19 outbreak [Internet]. Leuven: European Society for Gynaecological Endoscopy; c2020 [cited 2020 Apr 19]. Available from: https://esge.org/wpcontent/uploads/2020/04/ESGE-Gynaecological-surgeryduring-Covidoutbreak-updated-31-March-2020.pdf.

6. Society of American Gastrointestinal and Endoscopic Surgeons. SAGES and EAES recommendations regarding surgical recommendations surgical response to COVID 19 [Internet]. Los Angeles (CA): Society of American Gastrointestinal and Endoscopic Surgeons; c2020 [cite 2020 Apr 19]. Available from: https://www.sages.org/ recommendations-surgical-response-covid-19/25.

7. Royal College of Obstetricians and Gynaecologists (RCOG) (2020). RCOG/BSGE Statement on gynaecological laparoscopic procedures and COVID-19 [Internet]. London: Royal College of Obstetricians and Gynaecologists; c2020 [cited 2020 Apr 19]. Available from: https:// mk0britishsociep8d9m.kinstacdn.com/wpcontent/uploads/2020/03/Joint-RCOG-BSGE-Statement-ongynaecological-laparoscopic-procedures-and-COVID-19.pdf.

8. Morris SN, Fader AN, Milad MP, Dionisi HJ. Understanding the "scope" of the problem: why laparoscopy is considered safe during the COVID-19 pandemic. J Minim Invasive Gynecol 2020;27:789-91.

9. Gu J, Han B, Wang J. COVID-19: gastrointestinal manifestations and potential fecal-oral transmission. Gastroenterology 2020;158:1518-9.

10. Xiao F, Tang M, Zheng X, Liu Y, Li X, Shan H. Evidence 


\section{Obstetrics \& Gynecology Science}

Vol. 64, No. 3, 2021

for gastrointestinal infection of SARS-CoV-2. Gastroenterology 2020;158:1831-3.

11. Kwak HD, Kim SH, Seo YS, Song KJ. Detecting hepatitis $B$ virus in surgical smoke emitted during laparoscopic surgery. Occup Environ Med 2016;73:857-63.

12. Eubanks S, Newman L, Lucas G. Reduction of HIV transmission during laparoscopic procedures. Surg Laparosc Endosc 1993;3:2-5.

13. Chang L, Yan Y, Wang L. Coronavirus disease 2019: coronaviruses and blood safety. Transfus Med Rev 2020;34:75-80.

14. Kiykaç Altinbaş Ş, Tapisiz ÖL, Üstün Y. Gynecological laparoscopic surgery in the shade of COVID-19 pandemic. Turk J Med Sci 2020;50:659-63.

15. American Association of Gynecologic Laparoscopists. AAGL Joint society statement on elective surgery during COVID-19 Pandemic. [Internet]. Cypress (CA): American Association of Gynecologic Laparoscopists; c2020 [cited 2020 Apr 19]. Available from: https://www.aagl.org/covid-19/covid-19-joint-statement-on-elective-surgeries/.

16. Srivastava A, Nasta AM, Pathania BS, Sundaram E, Jani $K V$, Manickavasagam K, et al. Surgical practice recommendations for minimal access surgeons during COVID 19 pandemic-Indian inter-society directives. J Minim Access Surg 2020;16:195-200.
17. Pawar T, Pokharkar A, Gori J, Pandey D, Rohilla J, Dsouza $A$, et al. The technique and justification for minimally invasive surgery in COVID-19 pandemic: laparoscopic anterior resection for near obstructed rectal carcinoma. J Laparoendosc Adv Surg Tech A 2020;30:485-7.

18. Mallick R, Odejinmi F, Clark TJ. COVID 19 pandemic and gynaecological laparoscopic surgery: knowns and unknowns. Facts Views Vis Obgyn 2020;12:3-7.

19. Ti LK, Ang LS, Foong TW, Ng BSW. What we do when a COVID-19 patient needs an operation: operating room preparation and guidance. Can J Anaesth 2020;67:756-8.

20. Schwarz L, Tuech JJ. Is the use of laparoscopy in a COVID-19 epidemic free of risk? Br J Surg 2020;107:e188.

21. Bhattacharya K. Are surgeons in India prepared for COVID-19? Indian J Surg 2020 Apr 17 [Epub]. http://doi. org/10.1007/s12262-020-02185-z.

22. Gupta P, Kundra D, Khanna A, Kundra P, Rakhecha M, Bansal AA. Novel mechanism for pneumoperitoneum and aerosol diffusion in laparoscopy during COVID-19. Asian J Res Surg 2020;3:6-10.

23. Dash BB, Chawla S. Safety of gynaecological laparoscopic surgery in the era of COVID 19 pandemic: our experience. IJSR 2020 Jul [Epub]. https://doi.org/10.36106/ ijsr. 